\title{
Desempenho de genitores e populações segregantes de trigo sob estresse de calor
}

\author{
Davi Melo de Oliveira $\left({ }^{(*)}\right)$; Moacil Alves de Souza $\left({ }^{2}\right)$; Valterley Soares Rocha $\left({ }^{2}\right)$; Josiane Cristina de Assis ( $\left.{ }^{3}\right)$ \\ (') Embrapa Rondônia, Rodovia BR 364 - Km 5,5 - Zona Rural. Caixa Postal 127, 76815-800 Porto Velho (RO). \\ E-mail: dmo.agro@yahoo.com.br (*) Autor correspondente. \\ (2) Departamento de Fitotecnia, Universidade Federal de viçosa, Av. P.H. Rolfs, s/n. , 36570-000 Viçosa (MG). \\ E-mail:moacil@ufv.br; rsrocha@ufv.br \\ (3) Departamento de Genética e Melhoramento, Universidade Federal de Viçosa, Viçosa (MG).E-mail: josicrisa@yahoo.com.br
}

Recebido: 31/jul./2009; Aceito: 24/jun./2010

\begin{abstract}
Resumo
A expansão da triticultura para áreas com temperaturas mais elevadas, como o Brasil-Central, constitui-se uma das principais medidas para diminuir a importação de trigo. Assim, genótipos tolerantes ao calor serão de extrema importância para elevar a produtividade desta cultura. Objetivou-se com este trabalho detectar variabilidade genética para tolerância ao calor, identificar populações e genitores mais tolerantes e quantificar o efeito de altas temperaturas sobre estes genótipos de trigo. Foram realizados dois experimentos em Viçosa (MG), utilizando-se o delineamento látice quadrado 16x16 com duas repetições, composto por 240 famílias oriundas de oito populações segregantes mais 16 genitores. No primeiro experimento, semeado em fevereiro de 2007 (verão), foram avaliadas famílias $F_{2: 4}$ e no segundo, em junho de 2007 (inverno), famílias $F_{2: 5}$. Avaliaram-se os caracteres floração, altura de planta, produção de grãos e massa de mil grãos. Diferenças de temperatura da emergência ao florescimento foram determinantes na resposta dos genótipos entre os ambientes. Detectou-se variabilidade genética para tolerância ao calor entre genitores e populações segregantes de trigo. Todos os caracteres avaliados tiveram redução sob altas temperaturas, sendo a produção de grãos o caráter mais afetado, seguido da altura, floração e massa de mil grãos. Os genótipos mais tolerantes ao calor foram os genitores BR 24, Aliança e EP 93541 e as populações segregantes BH1 146/BR24// Aliança/EP93541, BR24/Aliança//EP93541/CPAC9662 e Aliança/EP93541// CPAC9662/Pioneiro.

Palavras-chave: Triticum aestivum L., altas temperaturas, melhoramento.
\end{abstract}

\section{Performance of wheat genitors and segregating populations under heat stress}

\section{Abstract}

The expansion of wheat crops to areas with higher temperatures, like the Central-Brazil, is one of the main actions to decrease the wheat importation. For this reason, heat tolerant genotypes are essentials. The objective of this study was to identify genetic variability for heat tolerance, to identify heat tolerant wheat populations and genitors, and to quantify the high temperature effects on those wheat genotypes. Two experiments were carried out in Viçosa, Minas Gerais State. A 16x16 square lattice design was used with two replications, where 240 families from eight segregating populations (30 families from each population) plus 16 genitors were evaluated. In the first experiment sowed in February 2007 (summer), $\mathrm{F}_{2 \cdot 4}$ families were evaluated. In the second one sowed in June 2007 (winter), $F_{2.5}$ families were evaluated. The flowering, plant height, grain yield, and thousand grain weight were evaluated. Different temperature conditions from emergence to flowering were crucial on genotype responses when compared the two environments. There was found genetic variability for heat tolerance between wheat genitors and segregating populations. All the evaluated traits presented reduction under high temperatures, being the grain yield the most affected, followed by plant height, flowering, and thousand grain weight. The genitors BR 24, Aliança, and EP 93541 and the populations BH1146/BR24//Aliança/EP93541, BR24/Aliança//EP93541/CPAC9662 and Aliança/EP93541//CPAC9662/Pioneiro were the most heat resistant.

Key words: Triticum aestivum L., high temperatures, wheat breeding. 


\section{INTRODUÇÃO}

O atual cenário da triticultura brasileira merece grande atençáo, visto que ainda se importa a maior parte do trigo consumido no Brasil (Agrianual, 2007). Desta forma, ações que visem à autossuficiência, como o aumento na produtividade, expansão da área cultivada e melhoria da qualidade do trigo nacional devem ser priorizadas.

Tradicionalmente, os Estados maiores produtores de trigo no Brasil localizam-se na Região Sul, que concentra mais de $90 \%$ da produçáo nacional (CONAB, 2007). Porém, tem-se constatado avanço da área cultivada com esta cultura na região do Brasil Central (Rossi e Neves, 2004) e com elevada produtividade. Segundo levantamentos da Conab (2007), em Estados como Goiás, Distrito Federal e Minas Gerais, a produtividade média está acima dos $4300 \mathrm{~kg} \mathrm{ha}^{-1}$, contra pouco mais de $2000 \mathrm{~kg} \mathrm{ha}^{-1} \mathrm{da}$ Regiāo Sul. Salienta-se, no entanto, que a produção de trigo na Região Central do Brasil engloba cultivo com irrigação.

O trigo é uma espécie originária de clima frio, e por esta razão seu desempenho produtivo é melhor em regióes com temperaturas mais amenas. Diversos trabalhos têm relatado o efeito negativo de temperaturas elevadas sobre a planta de trigo (CARGNin et al., 2006a; FoKar et al., 1998; Khanna-Chopra e Viswanathan, I 999; Lal et al., i 998; Rane e Nagarajan, 2004; Shah e Paulsen, 2003; Souza e Ramalho, 200 i; Yang et al., 2002). Segundo FOKAR et al. (1998), temperatura alta pode ser o maior fator de estresse ambiental limitante da produtividade de trigo, sendo a tolerância ao calor um importante objetivo nos programas de melhoramento.

O sucesso na expansão da cultura do trigo para regióes tropicais, a exemplo do Brasil - Central, só é possível com o desenvolvimento de cultivares com maior tolerância ao calor. Esse processo se faz necessário tendo em vista que em algumas áreas ou microrregióes as temperaturas são elevadas; além disso, existem áreas sujeitas a estresse térmico em cultivo de sequeiro no fim do verão, quando ainda há disponibilidade de chuvas (Souza e Ramalho, 200I).

Um fato que vem chamando a atenção nos últimos anos é o aquecimento global. Relatórios do Intergovernmental Panel on Climate Change (IPCC, 200I) apontam a diminuição da produção agrícola e extinção de animais e plantas como alguns dos prováveis impactos do aquecimento global na América Latina. Segundo Siqueira et al. (2000), os cenários climáticos futuros implicam redução média de $31 \%$ na produção nacional de grãos de trigo, sendo os efeitos mais depressivos projetados para a região Centro-Sul, especialmente a partir de 2030. Estes autores salientam também, que no Brasil são restritas as pesquisas relacionadas aos impactos do efeito estufa na agricultura e chamam a atenção para a atual sensibilidade dos genótipos avaliados, reforçando a necessidade de linhas de pesquisa nesta área.
Para Assad et al. (2004), medidas mitigadoras do efeito estufa e o melhoramento de plantas para estresses ambientais são as principais medidas para se contornar os danos causados pelo aquecimento global. Afirmam ainda que os programas de melhoramento devam levar em consideração a possibilidade de haver acréscimo mínimo de 1 a $3{ }^{\circ} \mathrm{C}$ da temperatura média do ar.

Os objetivos deste trabalho foram detectar variabilidade genética para tolerância ao calor, identificar genitores e populaçôes segregantes mais tolerantes e quantificar o efeito de altas temperaturas sobre estes genótipos de trigo.

\section{MATERIAL E MÉTODOS}

Para a determinação do efeito de altas temperaturas sobre a cultura do trigo, foram realizados dois experimentos no município de Viçosa, com coordenadas de 20045'14"S e 42052'54"W e altitude de $649 \mathrm{~m}$, na Zona da Mata do Estado de Minas Gerais. O primeiro experimento foi semeado em fevereiro de 2007, correspondendo à estação de verão (temperaturas elevadas) e o segundo, em junho de 2007, correspondendo à estação de inverno (temperaturas amenas).

Para minimizar a influência de fatores bióticos e abióticos sobre o crescimento e desenvolvimento das plantas, com exceção da temperatura como causadora de estresse por calor, os dois experimentos seguiram as mesmas recomendaçóes de cultivo e práticas culturais de uma lavoura irrigada, conforme as Informações Técnicas para a Cultura de Trigo na Região do Brasil - Central (Comissão..., 2005 ). Foram aplicados $250 \mathrm{~kg} \mathrm{ha}^{-1}$ de NPK da fórmula 08-28-16 no sulco de semeadura e posteriormente foram aplicados $50 \mathrm{~kg} \mathrm{ha}^{-1}$ de nitrogênio em cobertura sob a forma de sulfato de amônio, no início do perfilhamento.

Avaliaram-se os seguintes genótipos nos dois experimentos:

BH 1146 - desenvolvida pelo extinto Instituto Agronômico de Minas Gerais, foi cultivada em vários Estados brasileiros. Destaca-se pela sua excelente adaptação a ambientes adversos, sobretudo tolerância à seca e tolerância ao alumínio tóxico. Pela sua ampla adaptaçáo e ambiente de seleção em condiçôes de temperaturas elevadas, é considerada tolerante ao calor (Souza e Ramalho, 2001).

BR 24 - desenvolvida pela Embrapa Trigo; foi indicada para cultivo em condições de sequeiro no Brasil-Central. Possui colmos rígidos e há indicações de boa tolerância ao calor (Souza e Ramalho, 2001).

Aliança - desenvolvida pela Epamig, é recomendada para cultivo de sequeiro no Brasil-Central; tem se destacado pela sua tolerância à seca, boa palha e boa resistência às manchas foliares. Pelo seu bom desempenho nos mais diversos ambientes, provavelmente possui tolerância ao calor. 
EP 93541 - linhagem reunida em 1993 pelo programa de melhoramento de trigo da EPAMIG, não foi indicada para cultivo, porém comportou-se com boa tolerância ao calor (Souza e Ramalho, 2001).

CPAC 9662 - linhagem desenvolvida pela Embrapa Cerrados. Foi utilizada por apresentar porte baixo e bom tipo agronômico.

Pioneiro - cultivar desenvolvida pela UFV, é recomendada para cultivo no Brasil-Central. Esta cultivar possui boa adaptação para o cultivo irrigado.

BRS 207 - cultivar desenvolvida pela Embrapa Cerrados e recomendada para cultivo com irrigação no Brasil-Central. Possui porte baixo e alto potencial de produtividade de grãos.

Anahuac - cultivar de origem mexicana, desenvolvida pelo CIMMYT foi introduzida e recomendada para cultivo no Brasil na década de 1980. No Brasil-Central é cultivada com irrigação, possui ampla adaptação e tolerância ao calor (Souza e Ramalho, 2001)

Melhores famílias recombinantes do $10^{\circ}$ ciclo - BH1146/BR24; BR24/Aliança; Aliança/EP93541; EP93541/CPAC9662; CPAC9662/Pioneiro; Pioneiro/ BRS207; BRS207/ Anahuac; Anahuac/BH1146.

Populaçóes do 2.0 ciclo - BH1146/BR24//Aliança/EP93541; BR24/Aliança// EP93541/CPAC9662; Aliança/EP93541//CPAC9662/Pioneiro; EP93541/ CPAC9662//Pioneiro/BRS207; CPAC9662/Pioneiro//BRS207/Anahuac; Pioneiro/BRS207// Anahuac/ BH1146; BRS207/Anahuac//BH1146/BR24; Anahuac/ BH1146//BR24/ Aliança.

No experimento de verão foram avaliadas famílias $\mathrm{F}_{2: 4}$; as sementes derivadas de $\mathrm{F}_{2: 4}$ foram utilizadas na avaliação das famílias $\mathrm{F}_{2: 5}$ do experimento de inverno. Cada uma das oito populaçóes foi representada por 30 famílias, totalizando 240 , as quais foram avaliadas utilizando-se o delineamento látice quadrado $16 \times 16$, com duas repetiçóes. Para completar o látice, foram utilizados os oito genitores iniciais (cultivares) mais as oito melhores famílias recombinantes do primeiro ciclo de seleção recorrente.

Cada parcela foi constituída de três linhas de 3,0 m de comprimento, com espaçamento entre linhas de $18,6 \mathrm{~cm}$, conferindo área útil de $1,67 \mathrm{~m}^{2}$. A densidade de semeadura foi de 350 sementes aptas por $\mathrm{m}^{2}$. Foram coletados dados referentes aos seguintes caracteres: floração (dias) - determinada quando $50 \%$ das espigas estavam completamente emergidas; altura de plantas $(\mathrm{cm})$ - obtida pela média de cinco mediçóes do comprimento do colmo, ao acaso, em plantas na parcela; produção de grãos ( $\mathrm{g} / 1,67$ $\mathrm{m}^{2}$ ) - massa de grãos colhidos da parcela útil, depois de limpos e secos a $13 \%$ de umidade; massa de mil grãos $(\mathrm{g})$ - média obtida pela pesagem de quatro amostras de cem grãos e extrapolada para mil grãos.

Os dados dos caracteres avaliados nas duas épocas (verão e inverno) foram submetidos à análise de variância com o auxílio do software Mstat (I983), conforme o seguinte modelo:

$Y_{\mathrm{ijk}}=\mu+g_{\mathrm{i}}+r_{\mathrm{j}}+(b / r)_{\mathrm{jk}}+\varepsilon_{\mathrm{ij \textrm {k }}}$, em que: $Y_{\mathrm{ijk}}$ é o valor observado do genótipo $i$ no bloco $k$, dentro da repetiçáo $j$; $\mu$ é a média geral do experimento; $g_{\mathrm{i}}$ é o efeito do genótipo $i(i=1,2, \ldots, 256)$; $r_{i}$ é o efeito da repetição $j(j=1,2)$; $(b / r)_{\mathrm{ik}}$ é o efeito do bloco $k$ dentro da repetição $j(k=1$, $2, \ldots, 16$, para $j=1 ; k=17,18, \ldots, 32$, para $j=2) ; \varepsilon_{\mathrm{ijk}}$ é o erro aleatório associado à observaçáo $Y_{\mathrm{ij} \mathrm{k}}$.

Após a análise de variância de cada experimento e confirmada a homogeneidade das variâncias (CRUz et al., 2004), foi realizada a análise conjunta dos experimentos. Nesta análise utilizaram-se as médias ajustadas e adotouse o seguinte modelo:

$Y_{\mathrm{ilj}}=\mu+g_{\mathrm{i}}+a_{1}+b / a_{\mathrm{lj}}+g a_{\mathrm{il}}+\varepsilon_{\mathrm{ilj}}$, em que: $Y_{\mathrm{ilj}}$ é o valor observado do genótipo $i$ na repetiçáo j, dentro do ambiente $l ; \mu$ é a média geral do experimento; gi é o efeito do genótipo $i(i=1,2, \ldots, 256)$; $a_{1}$ é o efeito do ambiente $l(l=1,2)$; b/a $a_{1 \mathrm{j}}$ é o efeito da repetiçáo $j(j=$ $1,2)$ dentro do ambiente $l ; g a_{\mathrm{il}}$ é o efeito da interação entre o genótipo $i$ e o ambiente $l$; $\varepsilon_{\mathrm{ilj}}$ é o erro aleatório associado à observação $Y_{\text {ilj }}$. Os efeitos de genótipos e da interação genótipos por ambientes foram considerados aleatórios e o efeito de ambientes fixo, conforme CRUZ et al. (2004).

Para melhor caracterizaçáo dos efeitos da temperatura, foi determinada a soma térmica ou graus-dia acumulados $(G D A)$ em diferentes fases de desenvolvimento da cultura. Para este cálculo utilizou-se a expressão de ARNOLD (1959):

$$
G D A=\sum_{i=1}^{n}\left(T_{i}-T_{b}\right)
$$

onde Ti é a temperatura média $\left({ }^{\circ} \mathrm{C}\right)$ do dia; $T b$, é a temperatura-base $\left({ }^{\circ} \mathrm{C}\right)$ para a cultura do trigo; $n$, é o número de dias do período avaliado. Como temperatura-base adotou-se o valor de $4,5^{\circ} \mathrm{C}$ sugerido por FISCHER (I985) e utilizado por Khanna-Chopra e Viswanathan (1999). Este valor é considerado a temperatura mínima para o desenvolvimento da cultura, abaixo do qual o crescimento e o desenvolvimento da planta são interrompidos ou extremamente reduzidos.

Os genótipos foram classificados quanto à tolerância ao calor pelo índice de Fisher e MAURER (1978):

$I F M=\frac{(1-Y / Y p)}{D}$,

em que: $Y$ e $Y p$ são as médias de cada genótipo nos ambientes de estresse (verão) e sem estresse (inverno), respectivamente; $D=1-X / X p$, é a intensidade do estresse, sendo $X$ a média de todos os genótipos no ambiente de estresse e $X p$ a média de todos os genótipos no ambiente 
sem estresse. Genótipos com valores de IFM $\leq 0,5$ têm alta tolerância ao calor; com $0,5<$ IFM $\leq 1,0$ têm moderada tolerância ao calor e; IFM $>1,0$ são classificados como sensíveis ao calor.

Também foram expressas as médias das temperaturas mínima, média e máxima para diferentes fases do ciclo e para todo o ciclo da cultura. Estes dados foram coletados durante o período experimental pelo posto meteorológico localizado na UFV.

\section{RESULTADOS E DISCUSSÃO}

O desdobramento de famílias dentro de cada população, que reflete o grau de variabilidade genética dentro das populações, revelou significância para a maioria das características nos dois ambientes. Entretanto, para o caráter produção de grãos não foi constatada variabilidade nas populaçóes 3, 5 e 7 na época de verão e nas populaçóes 1 e 6 no inverno. O contraste famílias versus testemunhas propiciou significância para todos os caracteres nas duas épocas, exceto para altura de plantas na época de inverno e produção de grãos nas duas épocas, indicando não haver diferenças entre estas fontes de variação nas referidas condiçôes.

Pelas análises de variâncias conjuntas, constataram-se diferenças significativas $(\mathrm{p} \leq 0,01)$ das interaçóes genótipos $\mathrm{x}$ épocas, populaçôes $\mathrm{x}$ épocas e famílias dentro das populaçôes $\mathrm{x}$ épocas. $\mathrm{Na}$ interação testemunhas $\mathrm{x}$ épocas houve significância apenas para os caracteres floração e produção de grãos. A interação do contraste famílias vs. testemunhas $\mathrm{x}$ épocas foi significativa apenas para o caráter floração.

Todos os caracteres avaliados expressaram redução em seus valores médios na condiçáo de verão em comparação com o ambiente de inverno. As características floraçáo, altura, produção e massa de mil grãos revelaram médias de 43 dias, $73 \mathrm{~cm}, 269 \mathrm{~g} / 1,67 \mathrm{~m}^{2}$ e $35 \mathrm{~g}$ para o ambiente de verão e médias de 67 dias, $114 \mathrm{~cm}, 459 \mathrm{~g} / 1,67 \mathrm{~m}^{2}$ e 41 $\mathrm{g}$ para o ambiente de inverno, respectivamente. KHANnAChopra e Viswanathan (I999) verificaram que os genótipos com elevada regularidade da produção sob condição de estresse proporcionaram modesta produtividade, indicando que maior resistência ao estresse pode estar associada à média baixa.

Genótipos com esse tipo de comportamento possuem alta adaptabilidade a ambientes específicos (ambiente de verão), mas não são responsivos à melhoria do ambiente (inverno). No melhoramento para tolerância ao calor devese buscar por genótipos com menor oscilação do valor do caráter de interesse em ambientes contrastantes, mas associado com médias altas, ou seja, tolerantes e responsivos.

YANG et al. (2002) verificaram que o peso médio de gráos declinou de 55,6 para 27,9 mg quando a temperatura foi elevada de $20 / 15^{\circ} \mathrm{C}$ (dia/noite) para $30 / 25^{\circ} \mathrm{C}$ (dia/noite), redução de $49,8 \%$ sobre a expressão deste caráter. De fato, a síntese de amido no endosperma é interrompida pela inibição de diversas enzimas sob temperaturas altas, resultando em grãos com pontos esbranquiçados e foscos (CALEY et al., 1990) e, consequentemente, de menor massa.

Para produção de grãos, Khanna-Chopra e ViswaNATHAN (1999) constataram 33,9\% de redução quando compararam ambientes sem e com estresse de calor. Já YANG et al. (2002) verificaram que a média de produção de grãos reduziu de 1,51 para $0,69 \mathrm{~g} /$ espiga entre $20 / 15^{\circ} \mathrm{C}$ (dia/noite) e $30 / 25^{\circ} \mathrm{C}$ (dia/noite) respectivamente, correspondendo a $54,3 \%$ de redução.

Segundo Souza e Ramalho (200I), o calor afeta vários caracteres das plantas de trigo e, conseqüentemente, a produtividade de grãos. A reduçáo da produtividade pode ser devida ao acelerado desenvolvimento, acelerada senescência, aumento da respiração, redução da fotossíntese e inibição da síntese de amido no grão (KhannaChopra e Viswanathan, I999). Shah e Paulsen (2003) verificaram que a temperatura alta promoveu o declínio da fotossíntese, reduzindo a massa e o conteúdo de açúcar no grão.

Considerando-se as diferentes fases fenológicas e a média dos genótipos nos dois ambientes, foram necessários 194 graus-dia da emergência ao início do perfilhamento, 606 graus-dia do início do perfilhamento ao florescimento, 758 graus-dia do florescimento à maturaçáo e 1558 graus-dia para todo o ciclo (Tabela 1). Valores semelhantes foram observados por Hamada e Pinto (200I), trabalhando com a cultivar de trigo Tucuruí (IAC-24) em experimento realizado no município de Paranapanema no Estado de São Paulo.

Para prela e Ribeiro (2002), um dos métodos mais utilizados para relacionar a temperatura do ar com o desenvolvimento e/ou crescimento das plantas é o da soma térmica ou graus-dia acumulados, pois não depende da época e do local de plantio. Segundo hamada e pINTO (2001), há poucos estudos utilizando método dos graus-dia a fim de estimar a duração das fases fenológicas de trigo no Brasil, sendo oportunos estes estudos como subsídios aos trabalhos de zoneamento agrícola.

Não houve diferenças acentuadas entre as médias de temperatura na fase de florescimento-maturação nas duas épocas avaliadas. Este fato indica que ocorreram estresses térmicos em plantas de trigo semelhantes aos da fase de enchimento de grãos (florescimento-maturação), não sendo esta fase a determinante das diferenças de produtividade dos genótipos entre os dois ambientes. Desta forma, as diferenças entre as duas épocas devem-se, principalmente, aos estresses térmicos ocorridos nas fases iniciais, ou seja, da semeadura ao florescimento. Estudos de CARgnin et al. (2006b) revelaram que altas temperaturas podem prejudicar a planta de trigo já na fase de germinação.

Os resultados do teste de agrupamento de médias estão expressos na tabela 2 , bem como os valores do índice 
Tabela 1. Temperaturas médias (média, mínima e máxima), duração e graus-dia em diferentes fases de desenvolvimento de plantas de trigo no veráo e inverno de 2007, em Viçosa (MG)

\begin{tabular}{|c|c|c|c|}
\hline Fases do ciclo & Verão (V) & Inverno (I) & I - V \\
\hline \multicolumn{4}{|c|}{ Emergência - Início do Perfilhamento } \\
\hline \multicolumn{4}{|c|}{ Temperatura $\left({ }^{\circ} \mathrm{C}\right)$} \\
\hline Média & 22,3 & 16,2 & $-6,1$ \\
\hline Mínima & 17,6 & 10,7 & $-7,0$ \\
\hline Máxima & 29,7 & 25,0 & $-4,7$ \\
\hline Duração do período (dias) & 12 & 15 & 3 \\
\hline Duração acumulada (dias) & 12 & 15 & 3 \\
\hline Graus-dia no período & 213 & 175 & -38 \\
\hline Graus-dia acumulados & 213 & 175 & -38 \\
\hline \multicolumn{4}{|c|}{ Início do Perfilhamento - Florescimento } \\
\hline \multicolumn{4}{|c|}{ Temperatura $\left({ }^{\circ} \mathrm{C}\right)$} \\
\hline Média & 22,4 & 17,1 & $-5,3$ \\
\hline Mínima & 18,1 & 11,2 & $-6,9$ \\
\hline Máxima & 29,6 & 25,9 & $-3,7$ \\
\hline Duração do período (dias) & 31 & 52 & 21 \\
\hline Duração acumulada (dias) & 43 & 67 & 24 \\
\hline Graus-dia no período & 554 & 657 & 103 \\
\hline Graus-dia acumulados & 767 & 832 & 65 \\
\hline \multicolumn{4}{|c|}{ Florescimento - Maturação } \\
\hline \multicolumn{4}{|l|}{ Temperatura $\left({ }^{\circ} \mathrm{C}\right)$} \\
\hline Média & 18,7 & 20,1 & 1,4 \\
\hline Mínima & 14,2 & 14,3 & 0,1 \\
\hline Máxima & 26,0 & 27,9 & 1,9 \\
\hline Duração do período (dias) & 52 & 50 & -2 \\
\hline Duração acumulada (dias) & 95 & 117 & 22 \\
\hline Graus-dia no período & 739 & 778 & 39 \\
\hline Graus-dia acumulados & 1506 & 1610 & 104 \\
\hline \multicolumn{4}{|l|}{ Ciclo total } \\
\hline \multicolumn{4}{|l|}{ Temperatura $\left({ }^{\circ} \mathrm{C}\right)$} \\
\hline Média & 21,1 & 17,8 & $-3,3$ \\
\hline Mínima & 16,6 & 12,1 & $-4,5$ \\
\hline Máxima & 28,4 & 26,3 & $-2,1$ \\
\hline Duração (dias) & 95 & 117 & 22 \\
\hline Graus-dia & 1506 & 1610 & 104 \\
\hline
\end{tabular}

de tolerância ao calor (IFM) para produção de grãos. Nas quatro características avaliadas, constataram-se grupos distintos entre os genitores, cultivares homozigotas (genitores de 1 a 8 ) e as famílias utilizadas na recombinação para o ciclo 1 (genitores de 9 a 16). O contraste entre as famílias genitoras do ciclo 1 (genitores 9 a 16) foi menos acentuado do que entre os genitores homozigotos, sobretudo para o caráter produção de grãos. Quando se considera as médias das populaçôes recombinantes, não se constataram diferenças entre elas. Este resultado pode ser explicado pelo fato de estarem envolvidos quatro genitores na formação destas populaçôes, o que dilui o efeito isolado de cada genitor na média dos indivíduos da população.

Para classificar o desempenho dos genitores e populações diante do estresse de calor, foi determinado o IFM para os caracteres produção e massa de mil grãos, uma vez, que a produção e seus componentes são frequentemente usados como critério de seleção para tolerância ao calor
(Khanna-Chopra e Viswanathan, i999; Reynolds et al., I994).

Os valores de IFM para produção náo foram coincidentes com os obtidos para massa de mil grãos quanto à classificação dos genótipos, pois houve baixo coeficiente de correlação classificatória ou de Spearman $(\mathrm{r}=0,34$; $\mathrm{p} \leq 0,01)$. Como já dito anteriormente, as temperaturas médias da fase de floração até a maturação foram semelhantes entre as épocas, o que significa que as condiçôes térmicas foram semelhantes durante o enchimento de grãos. Por isso, outros componentes da produção, como número de grãos por espiga, teve maior efeito na definição da produção de grãos.

Ao analisar as médias de produção de grãos apresentadas na tabela 3, observa-se que os genótipos mais tolerantes ao calor e com desempenho superior também no inverno, foram os genitores BR 24, Aliança e EP 93541. Entretanto, ao analisar o IFM, nota-se certa incoerência, pois dentre os genótipos supracitados nenhum deles foi 
Tabela 2. Médias para os caracteres floração (FLO), altura da planta (ALT), massa de mil grãos (MMG), produção de grãos (PRO) e índice de tolerância ao calor para produção (IFM) de 16 genitores e oito populaçóes segregantes de trigo nas épocas de verão (V) e inverno (I) de 2007, em Viçosa (MG)

\begin{tabular}{|c|c|c|c|c|c|c|c|c|c|c|}
\hline \multirow{3}{*}{ Genótipos (1) } & \multicolumn{10}{|c|}{ Variáveis } \\
\hline & \multicolumn{2}{|c|}{ FLO (dias) } & \multicolumn{2}{|c|}{ ALT (cm) } & \multicolumn{2}{|c|}{ MMG (g) } & \multicolumn{3}{|c|}{ PRO (g 1,67m-2) } & \multirow{2}{*}{ IFM $^{(3)}$} \\
\hline & V & I & V & I & v & I & V & I & Média & \\
\hline \multicolumn{11}{|l|}{ Genitores } \\
\hline 1 & $44,9 b$ & $64,9 c$ & $89,2 \mathrm{a}$ & $136,1 \mathrm{a}$ & $33,1 \mathrm{~b}$ & $42,7 \mathrm{a}$ & $214,4 b$ & $524,2 \mathrm{a}$ & 369 & 1,43 \\
\hline 2 & $48,1 \mathrm{~b}$ & $67,9 \mathrm{~b}$ & $91,5 \mathrm{a}$ & $121,8 \mathrm{~b}$ & $32,3 \mathrm{~b}$ & $37,9 \mathrm{~b}$ & $386,7 \mathrm{a}$ & $506,6 \mathrm{a}$ & 447 & 0,57 \\
\hline 3 & $43,9 b$ & $68,1 \mathrm{~b}$ & $81,7 \mathrm{~b}$ & $111,4 b$ & $33,4 \mathrm{~b}$ & $38,5 b$ & 388,2 a & 536,7 a & 462 & 0,67 \\
\hline 4 & $42,3 \mathrm{~b}$ & $66,2 c$ & $71,6 \mathrm{~b}$ & 114,2 b & $34,0 \mathrm{a}$ & $39,8 \mathrm{a}$ & $327,4 \mathrm{a}$ & $680,3 \mathrm{a}$ & 504 & 1,25 \\
\hline 5 & $37,9 \mathrm{c}$ & $68,7 b$ & $51,9 d$ & $88,8 \mathrm{c}$ & $34,2 \mathrm{a}$ & $40,5 \mathrm{a}$ & 207,9 b & $421,1 \mathrm{~b}$ & 315 & 1,22 \\
\hline 6 & $38,9 \mathrm{c}$ & $67,6 \mathrm{~b}$ & $57,8 \mathrm{~d}$ & $97,9 \mathrm{c}$ & $31,9 \mathrm{~b}$ & $35,2 \mathrm{~b}$ & $250,9 b$ & 419,9 b & 335 & 0,97 \\
\hline 7 & $47,7 \mathrm{~b}$ & $71,0 \mathrm{a}$ & $71,0 \mathrm{~b}$ & $115,9 b$ & $33,2 \mathrm{~b}$ & $35,4 b$ & $309,4 \mathrm{a}$ & 320,7 b & 315 & 0,09 \\
\hline 8 & $44,3 b$ & $69,4 \mathrm{~b}$ & $67,0 \mathrm{c}$ & 102,7 c & $31,1 \mathrm{~b}$ & 34,7 b & 207,7 b & $376,8 \mathrm{~b}$ & 292 & 1,08 \\
\hline 9 & $46,4 \mathrm{~b}$ & $66,1 c$ & $79,0 \mathrm{~b}$ & $130,5 \mathrm{a}$ & $36,6 \mathrm{a}$ & $43,6 \mathrm{a}$ & 230,9 b & 583,2 a & 407 & 1,46 \\
\hline 10 & 52,9 a & $67,9 \mathrm{~b}$ & $76,3 \mathrm{~b}$ & $116,5 \mathrm{~b}$ & $36,1 \mathrm{a}$ & $41,6 \mathrm{a}$ & $251,1 \mathrm{~b}$ & 520,8 a & 386 & 1,25 \\
\hline 11 & $44,4 \mathrm{~b}$ & $67,6 \mathrm{~b}$ & $78,4 \mathrm{~b}$ & $116,5 b$ & $31,8 \mathrm{~b}$ & $41,3 \mathrm{a}$ & $231,8 \mathrm{~b}$ & $423,8 \mathrm{~b}$ & 328 & 1,09 \\
\hline 12 & $43,3 \mathrm{~b}$ & $68,4 \mathrm{~b}$ & $65,5 \mathrm{c}$ & 94,2 c & $35,3 a$ & 39,9 a & $215,7 b$ & $457,6 \mathrm{~b}$ & 337 & 1,28 \\
\hline 13 & 43,2 b & $69,1 \mathrm{~b}$ & $51,3 d$ & $100,1 \mathrm{c}$ & $35,8 \mathrm{a}$ & $39,4 \mathrm{a}$ & $248,6 \mathrm{~b}$ & 295,1 b & 272 & 0,38 \\
\hline 14 & $57,1 \mathrm{a}$ & $68,5 b$ & $62,2 \mathrm{c}$ & $115,1 \mathrm{~b}$ & $34,6 \mathrm{a}$ & $40,5 \mathrm{a}$ & $406,3 \mathrm{a}$ & $459,9 \mathrm{~b}$ & 433 & 0,28 \\
\hline 15 & $44,9 \mathrm{~b}$ & $71,9 \mathrm{a}$ & $63,7 c$ & $102,8 \mathrm{c}$ & 29,2 b & $37,1 \mathrm{~b}$ & $258,3 b$ & $307,4 \mathrm{~b}$ & 283 & 0,39 \\
\hline 16 & $46,4 \mathrm{~b}$ & $65,6 c$ & $78,2 \mathrm{~b}$ & 118,7 b & $36,1 \mathrm{a}$ & $42,0 \mathrm{a}$ & $265,5 b$ & $446,9 \mathrm{~b}$ & 356 & 0,98 \\
\hline \multicolumn{11}{|l|}{ Populações } \\
\hline 1 & $46,9 \mathrm{a}$ & $67,9 a$ & $78,6 \mathrm{a}$ & $115,2 \mathrm{a}$ & $34,7 \mathrm{a}$ & 39,9 a & $343,1 \mathrm{a}$ & 486,3 a & 415 & 0,71 \\
\hline 2 & $45,1 \mathrm{a}$ & $67,1 \mathrm{a}$ & $79,6 \mathrm{a}$ & $116,7 \mathrm{a}$ & $36,3 \mathrm{a}$ & $42,3 \mathrm{a}$ & 335,2 a & 522,9 a & 429 & 0,87 \\
\hline 3 & $41,1 \mathrm{~b}$ & $67,1 \mathrm{a}$ & $71,8 \mathrm{a}$ & $113,7 \mathrm{a}$ & $33,9 a$ & $39,5 \mathrm{a}$ & $276,8 \mathrm{a}$ & 459,0 a & 368 & 0,96 \\
\hline 4 & $40,5 b$ & $66,9 a$ & $70,6 \mathrm{a}$ & $112,9 a$ & $34,8 \mathrm{a}$ & $40,9 a$ & $260,2 \mathrm{a}$ & 470,9 a & 366 & 1,08 \\
\hline 5 & 39,4 b & $67,5 \mathrm{a}$ & $66,4 \mathrm{a}$ & $110,1 \mathrm{a}$ & $33,9 a$ & $39,7 \mathrm{a}$ & 208,3 a & $372,2 \mathrm{a}$ & 290 & 1,06 \\
\hline 6 & $40,3 \mathrm{~b}$ & $66,3 a$ & 67,9 a & 114,6 a & 33,9 a & $41,2 \mathrm{a}$ & $192,2 \mathrm{a}$ & $417,4 \mathrm{a}$ & 305 & 1,30 \\
\hline 7 & $42,8 \mathrm{~b}$ & $67,4 \mathrm{a}$ & $74,1 \mathrm{a}$ & $113,8 \mathrm{a}$ & $33,9 \mathrm{a}$ & $40,1 \mathrm{a}$ & $265,9 \mathrm{a}$ & $454,4 \mathrm{a}$ & 360 & 1,00 \\
\hline 8 & $45,3 \mathrm{a}$ & $64,6 \mathrm{a}$ & $76,1 \mathrm{a}$ & $116,5 \mathrm{a}$ & $35,1 \mathrm{a}$ & $42,3 \mathrm{a}$ & $263,6 \mathrm{a}$ & 488,3 a & 376 & 1,11 \\
\hline
\end{tabular}

Médias seguidas de mesma letra na coluna e no mesmo ambiente, para genitores e populaçóes, pertencem ao mesmo grupo, pelo teste de Scott e Knott ao nível de $5 \%$ de probabilidade.

(') Genitores: 1. BH1146; 2. BR24; 3. Aliança; 4. EP93541; 5. CPAC9662; 6. Pioneiro; 7. BRS207; 8. Anahuac; 9. BH1146/BR24; 10. BR24/Aliança; 11. Aliança/EP93541; 12. EP93541/CPAC9662; 13. CPAC9662/Pioneiro; 14. Pioneiro/BRS207; 15. BRS207/Anahuac; 16. Anahuac/BH1146. Populaçóes: 1. BH 1146 / BR 24 // Aliança / EP 93541; 2. BR 24 / Aliança // EP 93541 / CPAC 9662; 3. Aliança / EP93541 // CPAC 9662 / Pioneiro; 4. EP 93541 / CPAC 9662 // Pioneiro / BRS 207; 5. CPAC 9662 / Pioneiro // BRS 207 / Anahuac; 6. Pioneiro / BRS 207 // Anahuac / BH 1146; 7. BRS 207 / Anahuac // BH 1146 / BR 24; 8. Anahuac / BH 1146 // BR 24 / Aliança.

( $\left.{ }^{3}\right)$ IFM = Índice de Fischer e Maurer (1978). IFM $\leq$ 0,5: alta tolerância ao calor; 0,5<IFM $\leq 1,0$ : moderada tolerância ao calor; IFM >1,0: sensibilidade ao calor.

Tabela 3. Percentual de famílias dentro de cada população classificadas quanto à tolerância ao calor pelo índice de Fischer e Maurer (IFM) para produçáo de grãos

\begin{tabular}{|c|c|c|c|}
\hline \multirow{2}{*}{ Populações } & \multicolumn{3}{|c|}{$\%$} \\
\hline & IFM $\leq 0,5$ & $0,5<$ IFM $\leq 1,0$ & IFM $>1,0$ \\
\hline 1. BH1 146/BR24//Aliança/EP93541 & 36,67 & 36,67 & 26,67 \\
\hline 2. BR24/Aliança//EP93541/CPAC9662 & 23,33 & 46,67 & 30 \\
\hline 3. Aliança/EP93541//CPAC9662/Pioneiro & 6,67 & 63,33 & 30 \\
\hline 4. EP93541/CPAC9662//Pioneiro/BRS207 & 3,33 & 33,33 & 63,33 \\
\hline 5. CPAC9662/Pioneiro//BRS207/Anahuac & 16,67 & 36,67 & 46,67 \\
\hline 6. Pioneiro/BRS207//Anahuac/BH1146 & 3,33 & 20 & 76,67 \\
\hline 7. BRS207/Anahuac//BH1 146/BR24 & 13,33 & 36,67 & 50 \\
\hline 8. Anahuac/BH1 146//BR24/Aliança & 10 & 26,67 & 63,33 \\
\hline
\end{tabular}

IFM $\leq 0,5$ : alta tolerância ao calor; $0,5<$ IFM $\leq 1,0$ : moderada tolerância ao calor; IFM >1,0: sensibilidade ao calor.

classificado como altamente tolerante ao calor, apenas como moderadamente tolerantes e até como sensível ao calor, caso do genitor EP 93541. Entre as populaçôes segregantes não foram formados grupos de genótipos para o caráter produção; assim, além da média foi comparado também os valores do IFM. Desta forma, as melhores populaçôes foram a BH1146/BR24//Aliança/ EP93541, BR24/Aliança//EP93541/CPAC9662 e Aliança/EP93541//CPAC9662, que foram classificadas como moderadamente tolerantes ao calor. 
Em outros genótipos classificados como altamente tolerantes, mas sem atingir médias superiores nos dois ambientes, caso do genitor BRS 207, o menor valor de IFM foi de 0,09. Da forma como este índice é concebido, é possível ocorrer situaçóes de baixa consistência, sobretudo quando o contraste entre as médias de um determinado genótipo é pequeno nos dois ambientes. Uma alternativa é utilizar a média do genótipo associada ao IFM. Em alguns trabalhos, este índice foi utilizado sem maiores problemas (Khanna Chopra e Viswanathan, I999; YANG et al., 2002).

As populaçôes 1, 2 e 3 foram as que tiveram o maior número de famílias classificadas como tolerantes ou moderadamente tolerantes ao calor, corroborando com os menores valores de IFM obtidos por estas populaçóes (Tabela 3). Já as populaçôes 4,6 e 8 tiveram mais de $63 \%$ das famílias classificadas como susceptíveis às altas temperaturas.

\section{CONCLUSÕES}

1. Há variabilidade genética para tolerância ao calor em trigo.

2. Diferenças de temperatura entre as fases de emergência ao florescimento são determinantes nas variaçóes das características entre os ambientes.

3. Os genótipos com melhor desempenho produtivo em ambiente com estresse de calor e responsivos em ambiente favoráveis são os genitores BR 24, Aliança e EP 93541, as famílias recombinantes Pioneiro/ BRS207, BRS 207/Anahuac e Anahuac/BH1146, e as populações segregantes BH1146/BR24//Aliança/ EP93541 e BR24/Aliança//EP93541/ CPAC9662.

\section{REFERÊNCIAS}

AGRIANUAL. Anuário da Agricultura Brasileira. São Paulo: Agra FNP - Instituto FNP, 2007. 515p.

ARNOLD, C.Y. The determination and significance of the base temperature in a linear heat unit system. Journal of the American Society for Horticultural Science, v.74, p.430-445, 1959.

ASSAD, E.D.; PINTO, H.S.; ZULLO JÚNIOR, J.; ÁVILA, A.M.H. Impacto das mudanças climáticas no zoneamento agroclimático do café no Brasil. Pesquisa Agropecuária Brasileira, v.39, p.1057-1064, 2004.

CALEY, C.Y.; DULFUS, C.M.; JEFFCOAT, B. Effects of elevated temperature and reduced water uptake on enzymes of starch synthesis in developing wheat grains. Australian Journal of Plant Physiology, v.17, p.431-439, 1990.

CARGNIN, A.; SOUZA, M.A.; CARNEIRO, P.C.S.; SOFIATTI, $\mathrm{V}$. Interação entre genótipos e ambientes e implicaçóes em ganhos com seleção em trigo. Pesquisa Agropecuária Brasileira, v.41, p.987993, 2006a.
CARGNIN, A.; SOUZA, M.A.; DIAS, D.C.F.S.; MACHADO, J.C.; MACHADO, C.G.; SOFIATI, V. Tolerância ao estresse de calor em genótipos de trigo na fase de germinação. Bragantia, v.65, p.245-251, 2006b.

COMISSÃO CENTRO - BRASILEIRA DE PESQUISA DE TRIGO. Informaçóes técnicas para a cultura de trigo na Região do Brasil - Central: safras 2005 e 2006. Santo Antônio de Goiás: Embrapa Arroz e Feijáo; Planaltina, DF: Embrapa Cerrados; Passo Fundo: Embrapa Trigo, 2005. 85p.

CONAB. Companhia Nacional de Abastecimento. Avaliação da safra agrícola 2007/2008 - Segundo levantamento de intenção de plantio. nov., 2007. 26p.

CRUZ, C.D.; REGAZZI, A.J.; CARNEIRO, P.C.S. Modelos biométricos aplicados ao melhoramento genético. 3.ed. Viçosa: Editora UFV, 2004. 2v. v.1. 480p.

FISCHER, R.A. Number of kernels in wheat crops and the influence of solar radiation and temperature. Journal of Agricultural Science, v.105, p.447-461, 1985.

FISCHER, R.A.; MAURER, R. Drought resistance in spring wheat cultivars. I. Grain yield response. Australian Journal of Agricultural Research, v.29, p.897-907, 1978.

FOKAR, M.; NGUYEN, H.T.; BLUM, A. Heat tolerance in spring wheat. I. Estimating cellular thermo tolerance and its heritability. Euphytica, v.104, p.1-8, 1998.

HAMADA, E.; PINTO, H. S. Avaliação do desenvolvimento do trigo utilizando medidas radiométricas em função de graus-dia. In: SIMPÓSIO BRASILEIRO DE SENSORIAMENTO REMOTO, 10., 2001, Foz do Iguaçu. Anais.... São José dos Campos: INPE, 2001. p.95-101.

INTERGOVERNMENTAL PANEL ON CLIMATE CHANGE - IPCC. Climate change 2001: impacts, adaptation, and vulnerability. In: MACCARTHY, J.J.; CANZIANI, O.F.; LEARY, N.A.; DOKKEN, D.J.; WHITE, K.S. (Ed.). Cambridge: Cambridge University Press, 2001. 1032p.

KHANNA-CHOPRA, R.; VISWANATHAN, C. Evaluation of heat stress tolerance in irrigated environment of $T$. aestivum and related especies. I. Stability in yield and yield components. Euphytica, v.106, p.169-180, 1999.

LAL, M.; SINGH, K.K.; RATHORE, L.S.; SRINIVASAN, G.; SASEENDRAN, S.A. Vulnerability of rice and wheat yields in NW India to future changes in climate. Agricultural and Forest Meteorology, v.89, p.101-114, 1998.

MSTAT. Microcomputer statistical program. Michigan: Michigan State University, 1983.

PRELA, A.; RIBEIRO, A.M.A. Determinação de graus-dia acumulados e sua aplicação no planejamento do cultivo de feijãovagem (Phaseolus vulgaris L.) para Londrina-PR. Revista Brasileira de Agrometeorologia, v.10, p.83-86, 2002.

RANE, J.; NAGARAJAN, S. High temperature index - for field evaluation of heat tolerance in wheat varieties. Agricultural Systems, v.79, p.243-255, 2004 
REYNOLDS, M.P.; BALOTA, M.; DELGADO, M.I.B.; AMANI, I.; FISCHER, R.A. Physiological and morphological traits associated with spring wheat yield under hot, irrigated conditions. Australian Journal of Plant Physiology, v.21, p.717-730, 1994.

ROSSI, R.M.; NEVES, M.F. (Coord.). Estratégias para o trigo no Brasil. São Paulo: Atlas, 2004. 224p.

SHAH, N.H.; PAULSEN, G.M. Interaction of drought and high temperature on photosynthesis and grain-filling of wheat. Plant and Soil, v.257, p.219-226, 2003.
SIQUEIRA, O.J.W.; STEINMETZ, S.; FERREIRA, M.F; COSTA, A.C.; WOZNIAK, M.A. Mudanças climáticas projetadas através dos modelos GISS e reflexos na produção agrícola brasileira. Revista Brasileira de Agrometeorologia, v.8, p.311-320, 2000.

SOUZA, M.A.; RAMALHO, M.A.P. Controle genético e tolerância ao estresse de calor em populaçôes híbridas e em cultivares de trigo. Pesquisa Agropecuária Brasileira, v.36, p.1245-1253, 2001.

YANG, J.; SEARS, R.G.; GILL, B.S.; PAULSEN, G.M. Growth and senescence characteristics associated with tolerance of wheatalien amphiploids to high temperature under controlled conditions. Euphytica, v.126, p.185-193, 2002. 